\title{
CONCESSÃO DE USO EM UNIDADES DE CONSERVAÇÃo DE PROTEÇÃo INTEGRAL: A tramitação do Projeto de Lei 249/2013 E potenciais implicações da Lei 16.260/2016 no Estado de São Paulo
}

\author{
Fernanda Nogueira Lopes ${ }^{1}$, Maria Inez Pagani ${ }^{2}$, Julia Camara Assis ${ }^{3}$
}

\author{
1 Departamento de Ecologia, Instituto de Biociências, Universidade Estadual Paulista (UNESP), Av. 24A, 1515, Rio Claro, 13506-900, São Paulo-Brasil. \\ 2 Departamento de Ecologia, Instituto de Biociências, Universidade Estadual Paulista (UNESP), Av. 24A, 1515, Rio Claro, 13506-900, São Paulo - Brasil. \\ 3 Programa de Pós-graduação em Ecologia e Biodiversidade, Departamento de Ecologia, Instituto de Biociências, Universidade Estadual Paulista (UNESP), \\ Av. 24A, 1515, Rio Claro, 13506-900, São Paulo - Brasil. \\ *Autora para correspondência: feernanda.nl@gmail.com
}

Recebido em 24 de janeiro de 2019. Aceito em 17 de setembro de 2019. Publicado em 26 de setembro de 2019.

Resumo - Unidades de Conservação (UCs) são uma estratégia usual para a conservação da biodiversidade, porém, sem uma gestão integrada com a sociedade, não são suficientes para garantir a conservação ambiental. As limitações de gestão estão relacionadas com a falta de recursos financeiros e humanos dos órgãos governamentais responsáveis. A concessão das áreas de uso público de UCs começou sem uma legislação específica. Este trabalho teve como objetivo analisar a legislação vigente sobre o tema concessão de uso de áreas de UCs, a tramitação e as potenciais implicações do Projeto de Lei (PL) 249/13, aprovado na forma da Lei 16260/2016 no estado de SP. Foram feitos o levantamento e análise de documentos, totalizando 31 , entre eles estão: acadêmicos, notícias, manifestações formais e documentos legais. Identificamos que a tramitação do PL e a aprovação da Lei ocorreram sem uma ampla discussão com a sociedade e apoio técnico na sua elaboração, o que pode trazer implicações negativas. Mesmo com a lei em vigor, concluímos que ainda há possibilidades de atuação de Organizações Não Governamentais, Ministério Público entre outros, por meio de apoio técnico e legal na elaboração dos editais, planos de manejo e contratos de concessão e participação dos mesmos nas audiências públicas.

Palavras-chave: uso público; área protegida; exploração florestal; Plano de Manejo.

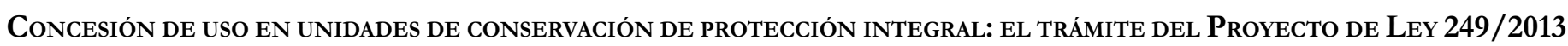
y posibles implicaciones de la Ley 16.260/2016 en el Estado de São Paulo

Resumen - Las Unidades de Conservación (Uds.C) son una estrategia común para la conservación de la biodiversidad, pero sin una gestión integrada con la sociedad no son suficientes para garantizar la conservación del medio ambiente. Las limitaciones de gestión están relacionadas con la falta de recursos financieros y humanos de las agencias gubernamentales responsables. La concesión de las áreas públicas de las Uds,C comenzó sin una legislación específica. El objetivo de este trabajo fue analizar la legislación actual sobre el tema de la concesión del uso de áreas de Uds, C, el trámite y las posibles implicaciones del Proyecto de Ley (PL) 249/13, aprobado de conformidad con la Ley 16260/2016 en el estado de SP. Se realizó el relevamiento y análisis de documentos, totalizando 31, entre ellos: académicos, noticias, manifestaciones formales y documentos legales. Identificamos que el trámite del proyecto de ley y la aprobación de la ley se produjo sin una discusión amplia con la sociedad y el apoyo técnico en su elaboración, lo que puede traer consecuencias negativas. Incluso con la ley vigente, concluimos que todavía hay posibilidades de acción por parte de las organizaciones no gubernamentales, el Ministerio Público, entre otros, a través del apoyo técnico y legal en la elaboración de los edictos, planes de gestión y contratos de concesión y su participación en audiencias públicas.

Palabras clave: uso público; área protegida; explotación forestal; Plan de Gestión. 
USE CONCESSION IN STRICTLY PROTECTED AREAS: BILl 249/2013 AND THE POTENTIAL IMPLICATIONS OF LAw 16.260/2016 IN the State of São Paulo

\begin{abstract}
Conservation Units (UC) are widely used as a strategy for biodiversity conservation, but without an integrated management with society, it might not guarantee environmental conservation. Management limitations are related to insufficient investment in financial and human resources by the responsible government agencies. The concession of public use areas of UCs began to be practiced in Brazil without specific legislation. This study evaluates the development and potential implications of the Bill 249/13, recently approved in the form of Law 16260/2016. A total of 31 documents were surveyed and analyzed, among them academic documents, news, formal manifestations and legal documents. The Billing process and the approval of the Law occurred without a wide discussion with society and without sufficient technical support in its elaboration, which can lead to negative implications. Even with the law in force, we highlight the possibilities for NGOs, Public Prosecutors and other independent professionals to engage in the concession process providing technical and legal support in the preparation of public notices, management plans, contracts and public hearings.
\end{abstract}

KEYwORDs: public use, protected area, logging, management plan.

\title{
INTRODUÇÃO
}

Uma das estratégias mais adotadas e um dos principais instrumentos para a conservação da biodiversidade é a criação de áreas protegidas. Existem exemplos de áreas protegidas em aproximadamente 80\% dos países do mundo (Mulongoy e Chape 2003). Algumas delas foram criadas ainda no século XIX, com a intenção de manter paisagens belas para as futuras gerações (Mulongoy e Chape 2003). O Parque Nacional (PARNA) de Yellowstone foi o primeiro a ser criado no mundo, em 1872, com o objetivo de preservar suas paisagens "intocadas" para as futuras gerações, onde o ser humano seria sempre somente um visitante e jamais um morador. Esse modelo foi adotado por muitos outros países e, em diversos deles, permanece até hoje (Bensusan 2006).

No Brasil, desde o Código Florestal (Decreto 23.793, de 1934), houve a inclusão das Unidades de Conservação (UC) na legislação e, em 1944, foi criada a seção de Parques Nacionais do Serviço Florestal para orientar, fiscalizar e coordenar os programas de trabalho para os parques nacionais. A Política Nacional do Meio Ambiente (PNMA), de agosto de 1981 (Lei 6.938/81), foi um marco legal para políticas públicas de meio ambiente a serem desenvolvidas pelo poder público. Ela instituiu o Sistema Nacional do Meio Ambiente (SISNAMA), que foi criado para coordenar e concretizar a PNMA. Entre os instrumentos da PNMA, o Artigo VI determina: "a criação de espaços territoriais especialmente protegidos pelo Poder Público federal, estadual e municipal, tais como áreas de proteção ambiental, de relevante interesse ecológico e reservas extrativistas" (Farias 2006). A Constituição Federal de 1988 (Capítulo VI, Artigo 225) reserva à população o direito a um "meio ambiente ecologicamente equilibrado" e a partir de então o poder público tem a obrigação de preservá-lo (Brasil 1988).

A partir desta base na Constituição e na PNMA, foi elaborado o Sistema Nacional de Unidades de Conservação (SNUC), instituído no Brasil em 2000 (Lei Federal 9.985/2000), que organiza as UCs em categorias, cada uma com objetivos específicos. (Brasil 2000).

As UCs do SNUC têm sua gestão feita pelo poder público por meio dos seguintes órgãos:

- O órgão consultivo e deliberativo é o Conselho Nacional do Meio Ambiente (CONAMA) com a função de acompanhar a implementação do SNUC;

- O órgão central, representado pelo Ministério do Meio Ambiente (MMA), que tem a finalidade de coordenar o SNUC; 
- O órgão executor representado na esfera federal, pelo Instituto Chico Mendes de Conservação da Biodiversidade (ICMBio) e pelo Instituto Brasileiro do Meio Ambiente e dos Recursos Naturais Renováveis (IBAMA), com a função de criar e administrar as UCs (Brasil 2000).

No Estado de São Paulo, a gestão é feita pela Secretaria do Meio Ambiente (SMA), mais especificamente pela Fundação Florestal (FF) e pelo Instituto Florestal (IF), respondendo por $47.594 \mathrm{~km}^{2}$ em Estações Ecológicas e $94.253 \mathrm{~km}^{2}$ em Parques Estaduais. O total de UCs de proteção integral em SP é de 367 com área de $159.190 \mathrm{~km}^{2}$ (CNUC 2018).

É importante ressaltar que a implantação de UCs não é suficiente para garantir a proteção integral dos recursos naturais e conservação destas áreas. As limitações de gestão giram em torno da dificuldade dos órgãos ambientais do governo (por exemplo, ICMBio) em disponibilizar os instrumentos necessários ao manejo das áreas. Os problemas mais comumente encontrados são: situação fundiária indefinida, caça, conflitos com populações humanas dentro das UCs, escassez de recursos humanos e financeiros para fins de segurança, manutenção, planejamento e execução de projetos de conservação, instabilidade política das agências de meio ambiente, falta de Plano de Manejo (PM), entre outros (Faria 2004; Brito 2010).

Um estudo realizado pelo MMA em 2009 demonstrou que os recursos financeiros destinados à implementação e manutenção das UCs federais e estaduais eram limitados naquela época, o que reduz a capacidade de gestão das UCs pelo órgão público e ameaça a manutenção destas áreas em longo prazo (Brasil 2009). Pela situação em que se encontram a maioria das UCs brasileiras, é possível afirmar que a escassez de recursos financeiros e humanos se mantém desde então, mesmo que não tenha sido quantificada em estudos científicos.

Na Lei 9.985/00 que cria o SNUC, há o Artigo 33 que cita a exploração comercial nas UCs: “Art. 33 Exploração comercial de produtos, subprodutos ou serviços dependerá de prévia autorização e sujeitará o explorador a pagamento (exceto APA e RPPN)" (Brasil 2000). Em 2002, no Decreto 4.340/02 que regulamentou o SNUC, constam nos artigos 25 e 29 informações sobre exploração. No Art. 25 há informações sobre a possibilidade de exploração de produtos e subprodutos em UCs, de acordo com os objetivos das categorias. E no Art. 29 informações sobre a necessidade de a autorização para a exploração comercial de produtos ou subprodutos estar fundamentada em estudos de viabilidade econômica elaborado pelo órgão executor da UC (Brasil 2002).

As concessões em UCs, através de parcerias do poder público com a iniciativa privada (PPP - parceria público privada), já são previstas em legislação. A Lei 11.079 de dezembro de 2004 institui normas gerais para as PPPs, que podem ser na modalidade administrativa ou patrocinada. Há um acordo de cooperação assinado pelo Ministério do Planejamento e MMA no ano de 2011, onde estão previstas as concessões em algumas UCs através de PPPs (ICMBio 2011; Brasil, 2011).

O responsável à época pela Divisão de Serviços de Apoio à Visitação do ICMBio, em 2012, apontou alimentação, hospedagem, transporte interno, atividades de aventura, lojas de souvenires e operação de centro de visitantes como os serviços passíveis de concessão em UCs. Ele justificou a concessão, nestes casos, como um meio de gerar emprego e renda com um efeito multiplicador nas economias locais, apesar de também afirmar que há mais experiência e capacidade operacional na iniciativa privada, com consequente agilidade em prestar os serviços citados com maior retorno financeiro para o ICMBio (Neves 2012).

O Brasil possui muitos Parques Nacionais e Estaduais, espaços naturais muito conhecidos entre os turistas. O uso público é uma das bases para criação de um parque prevista no SNUC, e identificou-se em 2014 que, existem quase 70 parques nacionais no país e apenas 26 deles estão abertos à visitação e somente 18 contam com infraestrutura suficiente (ISA 2014). Ao olharmos para o orçamento destinado para as áreas protegidas do Brasil, em comparação com outros países com PIB menores, o país investe cerca de $\mathrm{R} \$ 4,40$ por hectare de UC, enquanto na Argentina são $\mathrm{R} \$ 21,00$, na Costa Rica, $\mathrm{R} \$ 32,00$ e no México, $\mathrm{R} \$ 49,00$ por hectare (Medeiros 2011). Além disso, a relação de número de funcionários por hectares protegidos no Brasil em UCs é das piores do mundo: existe 1 
funcionário para cada 18.600 ha, enquanto na África do Sul existe 1 para cada 1.176 ha e na Argentina 1 para cada 2.400 ha (Medeiros 2011).

A precariedade da infraestrutura das UCs inviabiliza maior arrecadação de recursos pela exploração sustentável da visitação. O turismo é uma importante fonte de geração de renda para as UCs e o incentivo a este tipo de prática revigora o apoio público a estas áreas. Em 2008, o ICMBio recebeu em média R \$7,3 milhões com concessões que podem ser aliadas para melhorar o turismo O estudo "Pilares para a sustentabilidade financeira do SNUC", do MMA, mostrou que no mesmo ano, nos Parques Nacionais abertos à visitação, por exemplo, a arrecadação total foi de R \$ 18,8 milhões entre ingressos e concessões de serviços em geral. Nos anos de 2014 e 2015, segundo o Sistema de Gestão Integrada do ICMBio, houve geração de aproximadamente R \$ 64 milhões da fonte arrecadação de autofinanciamento (ingressos, concessões de restaurantes e pousadas, vendas de artigos, taxas sobre o direito de imagem, concessões florestais, inclusive de compensação ambiental) por meio de 29 parques nacionais (Oliveira 2017). Já em 2015, foi gerado aproximadamente R $\$ 72$ milhões da mesma fonte de arrecadação por meio de 31 parques. Aproximadamente $90 \%$ dos recursos financeiros levantados pelos parques são provenientes de duas UCs emblemáticas, Parque Nacional da Tijuca e Parque Nacional do Iguaçu (Oliveira 2017).

Demonstrada a relevância da temática de concessões em UCs no Brasil e, no caso deste trabalho, no Estado de SP, nosso objetivo foi analisar a legislação vigente no tema concessão de uso nas Unidades de Conservação de Proteção Integral e identificar aspectos restritivos e permissivos com relação à atuação das concessionárias no Estado de São Paulo a partir da nova regulamentação (PL 249/2013 aprovado na forma da Lei 16260/2016 em $\mathrm{SP})$, com base em documentos técnicos, contratos e notícias.

\section{O Projeto de Lei (PL) 249/2013 e A Lei 16260/2016}

A partir da observação destes problemas e impasses na gestão das UCs e falta de recursos, torna-se essencial uma mudança no modo de gestão. Os diversos debates e pesquisas sobre esse assunto contextualizam o surgimento do PL 249/2013 para instituir a concessão das áreas de uso público e a exploração florestal em UCs paulistas. Em 29 de junho de 2016 este PL foi aprovado e a Lei 16260/16 foi publicada no dia 30 de junho de 2016 no Diário Oficial do Estado de São Paulo (São Paulo 2016).

O termo concessão é definido como uma outorga pelo poder público de direitos ou poder à particulares. A concessão de uso é um contrato administrativo pelo qual o poder público atribui a utilização exclusiva de um bem de seu domínio a um particular, para que o explore segundo sua destinação específica em determinado intervalo de tempo (Iglecias 2015). A concessão é diferente da privatização, que vem do termo privado, e faz referência à dimensão não pública e não estatal, ou seja, aos interesses de ordem particular, voltados (ou não) ao lucro. Difere também da terceirização que é uma contratação de serviços e se refere à execução de atividades e serviços prestados por pessoas ou organizações para outras instituições (Iglecias 2015). O texto do PL apresentava a seguinte informação "Autoriza a Fazenda do Estado a conceder a exploração de serviços ou o uso, total ou parcial, de áreas em próprios estaduais nele especificados, por até 30 anos” (São Paulo 2013). Posteriormente na Lei aprovada o texto ficou: "Autoriza a Fazenda do Estado a conceder a exploração de serviços ou o uso, total ou parcial, de áreas em próprios estaduais que especifica e dá outras providências correlatas." (São Paulo 2016).

A Lei também prevê a exploração comercial de recursos madeireiros ou subprodutos florestais nas áreas previstas no PM para este fim após decisão favorável do órgão executor. Outras exigências citadas são as de que os objetivos de projetos científicos já tenham sido finalizados e a garantia de preservação de um banco genético. Os propósitos da concessão seriam: efetivar a proteção dos bens ambientais e viabilizar a obtenção de recursos para investimento na proteção das áreas. A fiscalização do cumprimento do contrato fica a cargo do Estado que continua responsável pela gestão e conservação das áreas (São Paulo 2016).

1 Acessível em < https://www.al.sp.gov.br/repositorio/legislacao/lei/2016/lei-16260-29.06.2016.htm> 
Há alguns pré-requisitos para que a concessão aconteça, como a existência de PM, compatibilidade dos serviços planejados com os objetivos da UC, aprovação da concessão pelo órgão gestor da UC, atendimento de todos os requisitos previstos no SNUC, aprovação do Conselho Consultivo do Sistema de Informação e Gestão de Áreas Protegidas e de Interesse Ambiental do Estado de São Paulo (SIGAP), do Conselho Consultivo da UC e do Conselho Estadual do Meio Ambiente (CONSEMA) com realização de audiência pública, exploração, única e exclusiva, de áreas de uso público (uso intensivo) e/ou de experimentação ou de manejo sustentável (São Paulo 2016).

O edital da licitação para exploração dos serviços deve conter os seguintes fatores: definição clara dos mecanismos de pagamentos, qualidade da proposta para executar operações de maneira a promover a proteção, conservação, preservação e restauração de recursos naturais e bens do Estado, as obras a serem realizadas que devem respeitar o PM, as formas que serão utilizadas para favorecer condições de desenvolvimento social e econômico das populações tradicionais existentes no entorno e dentro das áreas concedidas, valorização dos produtos e mão de obra local, a obrigatoriedade de dar um correto destino aos resíduos produzidos, o compromisso de impedimento da alimentação de animais pelos usuários e o impedimento de atividades que coloquem em risco a integridade dos ecossistemas (São Paulo 2016).

\section{A CONCESSÃo EM ÁREAS PROTEGIDAS}

No Brasil já existem alguns exemplos de concessões feitas pelo Governo Federal como, por exemplo, o Parque Nacional do Iguaçu (PNI) que possui uma área de 185.000 ha no Brasil e tem um contrato de concessão desde 1999, inicialmente com duração de 15 anos, prorrogado em 2014 até 2020. As visitações no Parque passaram de 175 mil pessoas em 2000, para 1,5 milhão em 2012 e já foram investidos R \$42 milhões em melhorias (Iglecias 2015). Observa-se no trabalho de Gorini; Mendes e Carvalho (2006) "Concessão de serviços e atrativos turísticos em áreas naturais protegidas: o caso do Parque Nacional do Iguaçu" que o relatório financeiro do PNI (somando ingressos, concessões e filmagens) passou de $\mathrm{R} \$ 4,49$ milhões em 2001 para $\mathrm{R} \$ 11,60$ milhões em 2005 (Gorini et al 2006).

Outros exemplos é o PARNA Serra dos Órgãos, onde a concessão iniciou-se em 2010 com a cobrança de ingressos, camping, abrigo de montanha, estacionamento e transporte interno. No PARNA da Tijuca, o parque mais visitado do Brasil, a concessão ocorre com a cobrança de ingressos, transporte interno, estacionamento e exploração comercial do centro de visitantes, iniciada em 2012 (ICMBio 2012 apud Braga 2015). Vale ressaltar que no PARNA da Tijuca há um acordo de cooperação entre o ICMBio, o Estado do RJ, a Prefeitura, a Companhia Municipal de Limpeza Urbana - COMLURB, a Empresa Municipal de Vigilância S/A., a Mitra Arquiepiscopal do Rio de Janeiro e a Secretaria do Patrimônio da União (SPU), do Ministério do Planejamento, Orçamento e Gestão, com a interveniência do MMA (ICMBio 2011).

Há exemplos também de PARNAs onde existe a prestação de serviços de turismo nos quais não houve qualquer processo de autorização. Como o PARNA do Itatiaia onde existem hotéis, pousadas, camping e outras estruturas de lazer (Barros 2003), o PARNA da Tijuca onde existe um heliporto e o PARNA das Sete Cidades onde há um hotel (Braga 2015).

Em vista do que foi apresentado, a Lei 16260/16 tem o potencial de organizar e regular a atuação do setor privado nas UCs contempladas. O trabalho foi desenvolvido concomitantemente com a tramitação do PL, e por isso, o enfoque da avaliação das implicações desta Lei está apoiado nos documentos que precedem sua aprovação. 


\section{Material e método}

Esta pesquisa é de natureza qualitativa do tipo pesquisa documental, na qual se utilizou alguns procedimentos da análise de conteúdo, segundo Bardin (2004) para análise de um corpus documental que contém: quatro documentos acadêmicos, oito notícias, cinco manifestações formais com relação ao PL, uma apresentação informativa do ICMBio, seis documentos legais e sete relacionados com concessões em UCs, sendo eles contratos, editais, projeto básico e aditivo de contrato (Quadro 1).

O corpus documental foi lido e analisado, quanto ao seu conteúdo de forma descritiva, com o objetivo de obtenção de informações relevantes sobre o tema concessão em áreas protegidas e delineamento da tramitação do PL 249/2013. A leitura dos documentos permitiu o diagnóstico do posicionamento e visão dos autores, a identificação das bases legais e concessões vigentes e abordagens acadêmicas sobre a temática.

Quadro 1. Corpus Documental (Quadro elaborado pela autora)

\begin{tabular}{|c|c|c|c|}
\hline Data & $\begin{array}{l}\text { Tipo de } \\
\text { documento }\end{array}$ & $\begin{array}{l}\text { Nome e Informações do } \\
\text { documento }\end{array}$ & Link, autor ou fonte. \\
\hline 2000 & Lei & $\begin{array}{l}\text { Sistema Nacional do Meio ambiente- } \\
\text { Lei } 9.985 / 2000\end{array}$ & $\begin{array}{l}\text { http://www.planalto.gov.br/ccivil_03/leis/ } \\
\text { L9985.htm }\end{array}$ \\
\hline 2004 & Lei & $\begin{array}{l}\text { Lei } 11.079 / 2004 \text {, institui normas } \\
\text { gerais para licitação e contratação de } \\
\text { parceria público-privada no âmbito da } \\
\text { administração pública. }\end{array}$ & $\begin{array}{l}\text { http://www.planalto.gov.br/ccivil_03/_ } \\
\text { ato2004-2006/2004/lei/111079.htm }\end{array}$ \\
\hline 2006 & $\begin{array}{l}\text { Artigo } \\
\text { científico }\end{array}$ & $\begin{array}{l}\text { "Concessão de serviços e atrativos } \\
\text { turísticos em áreas naturais protegidas: } \\
\text { o caso do Parque Nacional do } \\
\text { Iguaçu." }\end{array}$ & $\begin{array}{l}\text { http://www.bndes.gov.br/SiteBNDES/ } \\
\text { bndes/bndes_pt/Institucional/ } \\
\text { Publicacoes/Consulta_Expressa/Setor/ } \\
\text { Turismo/200609_11.html }\end{array}$ \\
\hline 2009 & $\begin{array}{l}\text { Tese de } \\
\text { Doutorado }\end{array}$ & $\begin{array}{l}\text { "O uso do público nos parques } \\
\text { nacionais: a relação entre as esferas } \\
\text { pública e privada na apropriação da } \\
\text { biodiversidade" }\end{array}$ & $\begin{array}{l}\text { http://repositorio.unb.br/ } \\
\text { handle/10482/3826 }\end{array}$ \\
\hline 2010 & Contrato & $\begin{array}{l}\text { Contrato de concessão de prestação } \\
\text { de serviços em Unidade de } \\
\text { Conservação Federal entre ICMBIo e } \\
\text { empresa cataratas do Iguaçu S/A }\end{array}$ & Jorge Madeira e Larissa Diehl \\
\hline 2010 & Edital & $\begin{array}{l}\text { Edital de licitação na modalidade } \\
\text { concorrência do tipo técnica e } \\
\text { preço. Parque Nacional Fernando de } \\
\text { Noronha }\end{array}$ & Jorge Madeira e Larissa Diehl \\
\hline 2010 & Edital & $\begin{array}{l}\text { Edital de licitação na modalidade } \\
\text { concorrência do tipo maior lance ou } \\
\text { oferta. Parque Nacional da Tijuca }\end{array}$ & Jorge Madeira e Larissa Diehl \\
\hline 2011 & Parecer & $\begin{array}{l}\text { Parecer da Procuradoria Federal } \\
\text { Especializada- ICMBio sobre } \\
\text { as modalidades de delegação de } \\
\text { prestação de serviços de apoio a } \\
\text { visitação em UCs federais, } 2011\end{array}$ & Jorge Madeira e Larissa Diehl \\
\hline 2012 & Contrato & $\begin{array}{l}\text { Contrato de concessão de serviços de } \\
\text { apoio ao uso público entre o ICMBio } \\
\text { e a empresa Paineiras-Corcovado } \\
\text { LTDA }\end{array}$ & Jorge Madeira e Larissa Diehl \\
\hline 2012 & Projeto básico & $\begin{array}{l}\text { Projeto básico concessão de prestação } \\
\text { de serviços de apoio a visitação } \\
\text { pública e cobrança de ingressos - } \\
\text { complexo paineiras }\end{array}$ & Jorge Madeira e Larissa Diehl \\
\hline
\end{tabular}




\begin{tabular}{|c|c|c|c|}
\hline Data & $\begin{array}{l}\text { Tipo de } \\
\text { documento }\end{array}$ & $\begin{array}{l}\text { Nome e Informações do } \\
\text { documento }\end{array}$ & Link, autor ou fonte. \\
\hline 2013 & $\begin{array}{l}\text { Dissertação de } \\
\text { Mestrado }\end{array}$ & $\begin{array}{l}\text { "Viabilização do uso público de } \\
\text { parques nacionais e a disponibilização } \\
\text { por particulares de serviços de apoio à } \\
\text { visitação" }\end{array}$ & $\begin{array}{l}\text { http://repositorio.uniceub.br/ } \\
\text { handle/235/5914 }\end{array}$ \\
\hline 2013 & Projeto de Lei & $\begin{array}{l}\text { Projeto de lei } 249 / 2013 \text {, autoriza } \\
\text { a Fazenda do Estado a conceder o } \\
\text { uso de áreas públicas inseridas em } \\
\text { Unidades de Conservação da Natureza } \\
\text { que especifica, bem como dos } \\
\text { imóveis localizados nos Municípios de } \\
\text { Itirapina e Cajuru, e dá providências } \\
\text { correlatas. }\end{array}$ & $\begin{array}{l}\text { http://www.al.sp.gov.br/ } \\
\text { propositura/?id=1131130 }\end{array}$ \\
\hline 2013 & Emendas & $\begin{array}{l}\text { Emendas sugeridas ao PL } 249 \text { por } \\
\text { deputados, } 2013 \text {. }\end{array}$ & $\begin{array}{l}\text { http://www.al.sp.gov.br/ } \\
\text { propositura/?id=1130646 }\end{array}$ \\
\hline 2014 & Notícia & $\begin{array}{l}\text { "Projeto paulista legaliza concessões } \\
\text { em parques estaduais" - Jornal O Eco, } \\
2016\end{array}$ & $\begin{array}{l}\text { http://www.oeco.org.br/ } \\
\text { reportagens/27999-projeto-paulista-legaliza- } \\
\text { concessoes-em-parques-estaduais/ }\end{array}$ \\
\hline 2014 & Contrato & $\begin{array}{l}\text { Contrato de concessão de área da } \\
\text { União para exploração de serviços } \\
\text { de transporte ferroviário no Parque } \\
\text { Nacional da Tijuca entre o ICMBio } \\
\text { e a empresa Esfeco Administração } \\
\text { LTDA }\end{array}$ & Jorge Madeira e Larissa Diehl \\
\hline $01 / 03 / 2015$ & Aditivo & $\begin{array}{l}\text { Aditivo ao contrato de concessão } \\
\text { entre o ICMBio e a empresa Trem do } \\
\text { Corcovado LTDA. }\end{array}$ & Jorge Madeira e Larissa Diehl \\
\hline $24 / 06 / 2015$ & Notícia & $\begin{array}{l}\text { Promotor afirma que projeto de } \\
\text { Alckmin sobre áreas florestais é } \\
\text { inconstitucional }\end{array}$ & $\begin{array}{l}\text { https://www.redebrasilatual.com.br/ } \\
\text { ambiente/2015/06/cheque-em-branco-pl- } \\
\text { de-alckmin-esta-em-conflito-com-a-com-lei- } \\
\text { paulista-1529/ }\end{array}$ \\
\hline $03 / 07 / 2015$ & Inquérito Civil & $\begin{array}{l}\text { Inquérito civil assinado por promotor } \\
\text { de Justiça do GAEMA PCJ- } \\
\text { Piracicaba }\end{array}$ & $\begin{array}{l}\text { http://www.al.sp.gov.br/spl/2015/07/ } \\
\text { Acessorio/1268316_50250676_Acessorio. } \\
\text { pdf }\end{array}$ \\
\hline $19 / 06 / 2015$ & Notícia & $\begin{array}{l}\text { "Prefeitura de Ubatuba reivindica } \\
\text { controle do núcleo Picinguaba do } \\
\text { Parque da Serra do Mar" - Jornal Rede } \\
\text { Brasil Atual, } 2015\end{array}$ & $\begin{array}{l}\text { http://www.redebrasilatual.com.br/ } \\
\text { ambiente/2015/06/prefeitura-de-ubatuba- } \\
\text { quer-prioridade-em-concessao-de-uso-do- } \\
\text { parque-da-serra-do-mar-5589.html }\end{array}$ \\
\hline $23 / 04 / 2015$ & Notícia & $\begin{array}{l}\text { "Itirapina: Reunião pública discutirá } \\
\text { uso de área do Estado" - Jornal } \\
\text { Primeira Página, } 2015\end{array}$ & $\begin{array}{l}\text { http://www.jornalpp.com.br/politica/ } \\
\text { item/94682-itirapina-reuniao-publica- } \\
\text { discutira-uso-de-area-do-estado }\end{array}$ \\
\hline 2016 & Nota & $\begin{array}{l}\text { Nota enviada à secretária do Meio } \\
\text { Ambiente Patricia Iglecias por } \\
\text { representantes de ONGs e institutos } \\
\text { ambientais. }\end{array}$ & Roberto Resende \\
\hline Junho 2016 & Moção & $\begin{array}{l}\text { Moção do Conselho Universitário da } \\
\text { Unesp publicada }\end{array}$ & Dra. Maria Inez Pagani \\
\hline Junho 2016 & Ofício & $\begin{array}{l}\text { Ofício enviado pela Prefeitura de } \\
\text { Ubatuba para Assembleia Legislativa } \\
\text { de São Paulo }\end{array}$ & Ricardo Guterman \\
\hline 2016 & Ata & $\begin{array}{l}\text { Ata de Reunião da Comissão de } \\
\text { Meio Ambiente e Desenvolvimento } \\
\text { Sustentável da Assembleia Legislativa } \\
\text { do Estado de São Paulo }\end{array}$ & $\begin{array}{l}\text { http://www.al.sp.gov.br/alesp/comissao-at } \\
\text { a/?idAta=10153\&comissao=12453\&legisla } \\
\text { tura }=18\end{array}$ \\
\hline
\end{tabular}




\begin{tabular}{|c|c|c|c|}
\hline Data & $\begin{array}{l}\text { Tipo de } \\
\text { documento }\end{array}$ & $\begin{array}{l}\text { Nome e Informações do } \\
\text { documento }\end{array}$ & Link, autor ou fonte. \\
\hline 2016 & Apresentação & $\begin{array}{l}\text { Tema: Delegação de serviços de } \\
\text { apoio à visitação - Ministério do Meio } \\
\text { Ambiente, Divisão de Serviços de } \\
\text { Apoio à Visitação }\end{array}$ & $\begin{array}{l}\text { http://docplayer.com.br/19335591- } \\
\text { Delegacao-de-servicos-de-apoio-a-visitacao- } \\
\text { ministerio-do-meio-ambiente.html }\end{array}$ \\
\hline 07/06/2016 & Notícia & $\begin{array}{l}\text { “Alckmin amplia proposta e agora } \\
\text { quer 'privatizar’ } 25 \text { parques de São } \\
\text { Paulo" - Jornal Folha, } 2016\end{array}$ & $\begin{array}{l}\text { http://www1.folha.uol.com.br/ } \\
\text { cotidiano/2016/06/1778980-governo- } \\
\text { alckmin-quer-conceder-25-parques-a- } \\
\text { iniciativa-privada.shtml }\end{array}$ \\
\hline 07/06/2016 & Notícia & $\begin{array}{l}\text { "Assembleia aprova projeto que } \\
\text { "privatiza' } 25 \text { parques de SP"- Jornal } \\
\text { Estadão, } 2016\end{array}$ & $\begin{array}{l}\text { http://sustentabilidade.estadao.com. } \\
\text { br/noticias/geral,assembleia-aprova- } \\
\text { projeto-que-privatiza-25-parques-de- } \\
\text { sp,10000055809 }\end{array}$ \\
\hline 09/06/2016 & Notícia & $\begin{array}{l}\text { "Entregar nossos parques estaduais a } \\
\text { empresas privadas é solução?" - Blog } \\
\text { de Raquel Rolnik, 2016. }\end{array}$ & $\begin{array}{l}\text { https://raquelrolnik.wordpress. } \\
\text { com/2016/06/09/entregar-nossos-parques- } \\
\text { estaduais-a-empresas-privadas-e-solucao/ }\end{array}$ \\
\hline 08/06/2016 & Notícia & $\begin{array}{l}\text { "Concessão pode gerar cobrança de } \\
\text { entrada em parques, diz secretária" - } \\
\text { jornal G1 São Paulo, } 2016\end{array}$ & $\begin{array}{l}\text { http://g1.globo.com/sao-paulo/ } \\
\text { noticia/2016/06/concessao-pode-gerar- } \\
\text { cobranca-de-entrada-em-parques-diz- } \\
\text { secretaria.html }\end{array}$ \\
\hline 08/07/2016 & Notícia & $\begin{array}{l}\text { "Assembleia de São Paulo aprova } \\
\text { concessão de } 25 \text { áreas protegidas" - } \\
\text { Jornal O Eco, } 2016\end{array}$ & $\begin{array}{l}\text { http://www.oeco.org.br/noticias/ } \\
\text { assembleia-de-sao-paulo-aprova-concessao- } \\
\text { de-25-areas-protegidas/ }\end{array}$ \\
\hline 2016 & $\begin{array}{l}\text { Dissertação de } \\
\text { mestrado }\end{array}$ & $\begin{array}{l}\text { "Parcerias entre o setor público e o } \\
\text { setor privado: uma análise sobre os } \\
\text { elementos de estrutura e governança" }\end{array}$ & Marília Camara de Assis \\
\hline 2016 & Lei & $\begin{array}{l}\text { Lei } 16.260 / 2016 \text {, autoriza a Fazenda } \\
\text { do Estado a conceder a exploração } \\
\text { de serviços ou o uso, total ou parcial, } \\
\text { de áreas em próprios estaduais que } \\
\text { especifica e dá outras providências } \\
\text { correlatas. }\end{array}$ & $\begin{array}{l}\text { http: } / / \text { www.al.sp.gov.br/ } \\
\text { norma/?tipo=Lei\&numero }=16260 \& \text { ano }=2016\end{array}$ \\
\hline
\end{tabular}

\section{Resultados e Discussão}

A cronologia dos documentos e fatos mais relevantes do processo de tramitação do PL incluem concessões que exemplificam essa prática comum em vigência em algumas UCs e o posicionamento público por meio de ofício e outros documentos, manifestado por alguns órgãos governamentais ou da sociedade civil, esquematizados na Figura 1.

Além disso, o PL foi o foco de notícias ao longo de 2015 e mais intensamente em 2016, anteriormente à sua aprovação como Lei 16.260. Parte dessas notícias está destacada na cronologia (Figura 1). Outro aspecto que merece destaque consiste na exoneração da Secretária estadual do Meio Ambiente à época, logo após a publicação da Lei. 
Figura 1. Cronologia com os principais documentos analisados neste trabalho e fatos importantes relacionados à tramitação do PL 249/2013. Alguns eventos anteriores a 2013 foram incluídos na figura, pois foram analisados como exemplos de concessão já existentes antes do PL 249/2013 e Lei 16.260/2016. As linhas tracejadas separam os anos; a linha preta destaca o período de tramitação do PL. A seta na vertical representa a linha do tempo e os eventos estão simbolizados com o mês e ano em que ocorreram. As estrelas azuis destacam as notícias analisadas e as amarelas pontuam acontecimentos importantes no processo.

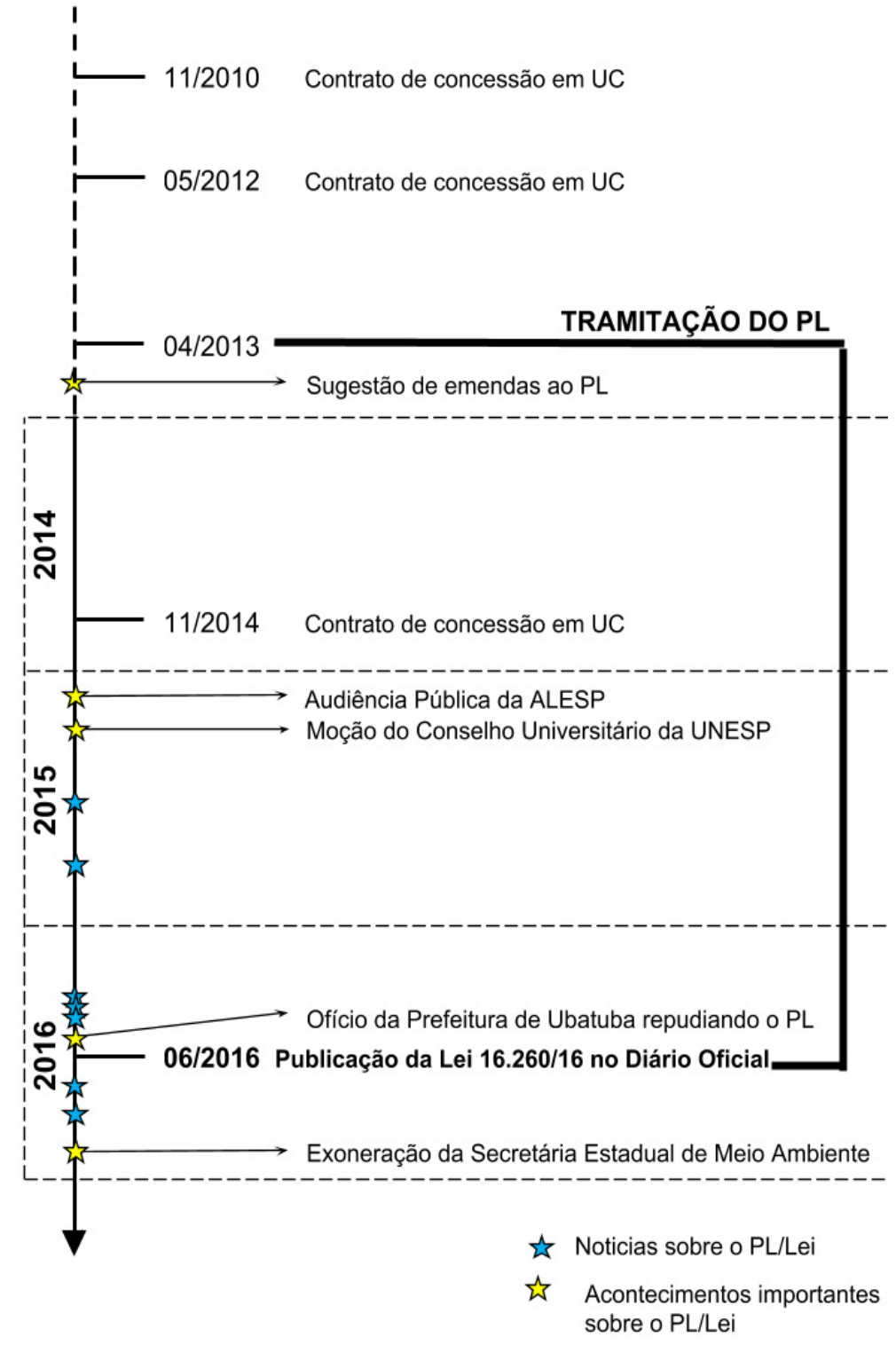

Fonte: Elaborada pelas autoras.

\section{Documentos relacionados com concessões em vigência nas UCs}

Apesar de não existir, até 2016 no estado de São Paulo, uma Lei direcionada às concessões em UCs, existem contratos em vigor. Estes contratos de concessões foram baseados até então em um parecer da Procuradoria Federal Especializada (PFE) do ICMBio publicado em 2011 (ICMBio 2011). Este documento afirma que os PARNA não são bens de uso comum do povo e sim bens públicos de uso especial e lembra que a finalidade primordial da visitação pública em UCs não é arrecadar fundos e sim realizar a promoção de educação ambiental e a conscientização para a preservação da natureza. A exploração por terceiros das atividades de apoio à visitação e uso público em UCs está descrita em legislação anterior, que o documento em questão também menciona (Decreto 4340/2002, Lei 9985/2000, Lei 9074/1995, Lei 8987/1995) enfatizando que somente a alusão à autorização que há 
nessa legislação não é suficiente. Porém, em nenhum ponto há a explicação de que forma deveriam ser realizadas essas concessões.

Em outro trecho, o Parecer demonstra que a utilização da legislação existente até o momento, analogamente, se justifica com as similaridades da utilização de terceiros da exploração das atividades em UCs e a concessão de serviços públicos quaisquer, como mostrado na Lei 8987/1995. Mas, o documento é enfático ao mencionar que o resultado das concessões não está focado exatamente no uso público, mas sim na operacionalização das atividades. Também não deixa dúvidas de que essa concessão da exploração do uso público em UCs necessitava de uma legislação própria, garantindo segurança jurídica ao processo e disciplinando suas especificidades.

\section{Da tramitação do PL ao texto da Lei}

O PL 249, de 30 de abril de 2013 de autoria do Governador Geraldo Alckmin, primeiramente autorizava a Fazenda do Estado a conceder o uso de áreas públicas inseridas em algumas UCs (Parque Estadual de Campos do Jordão, Parque Estadual da Cantareira, Parque Estadual do Jaraguá) e as áreas públicas da Estação Experimental de Itirapina e Floresta Estadual de Cajuru. O PL recebeu 11 emendas (Quadro 2) e uma Emenda Aglutinativa adicionando o nome de 25 Parques (Anexo A da Lei $^{2}$ ), todas as emendas foram rejeitadas. No dia 10/06 foi publicado ofício da Prefeitura Municipal de Ubatuba ${ }^{3}$, manifestando-se contra a inclusão dos Parques de sua região no PL (para detalhes da tramitação do PL, ver Apêndice 1).

Quadro 2. Emendas propostas ao Projeto de Lei 249 de 2013.

\begin{tabular}{|c|c|c|}
\hline $\mathbf{N}^{\circ}$ Emenda & Autores/Deputados & Síntese do Texto da emenda proposta (pela autora) \\
\hline 1 & Beth Sahão & Altera o prazo de concessão de 30 para 15 anos \\
\hline 2 & Luiz Claudio Marcolino & $\begin{array}{l}\text { Inclui dois parágrafos no Artigo } 1^{\circ} \text {, dizendo que os preços do ingresso não } \\
\text { poderiam ser superiores aos vigentes no dia da assinatura do contrato de } \\
\text { concessão, permitindo correção anual, e que os valores dos alimentos devem } \\
\text { ser acessíveis. }\end{array}$ \\
\hline 3 & Luiz Claudio Marcolino & $\begin{array}{l}\text { Altera o texto do "Artigo } 4^{\circ} \text { - (...) } \\
\text { "III - o recolhimento de contraprestação pecuniária pela concessionária, } \\
\text { exceto nos próprios estaduais especificados no inciso I do art. } 1^{\circ} . \text { " }\end{array}$ \\
\hline 4 & Luiz Claudio Marcolino & $\begin{array}{l}\text { Acrescenta aos } \int 1^{\circ} \text { e } 2^{\circ} \text { do artigo } 4^{\circ} \text { os itens: } \\
\text {-Controle social da concessão pelo Conselho Gestor de cada Unidade } \\
\text { - Controle social da concessão pelo Conselho Gestor integrado das Estações } \\
\text { Ecológicas e Experimental. }\end{array}$ \\
\hline 5 & Luiz Claudio Marcolino & $\begin{array}{l}\text { Altera a redação do item do } \int 3^{\circ} \text { do artigo } 4^{\circ} \text {, incluindo: a elaboração pela } \\
\text { concessionária do Plano de Manejo para a Floresta Estadual de Cajuru, } \\
\text { submetido à aprovação do CONSEMA. }\end{array}$ \\
\hline 6 & Luiz Claudio Marcolino & $\begin{array}{l}\text { Propõe a redação do item } 1 \text { do parágrafo único do artigo } 2^{\circ} \text { : existência de } \\
\text { Plano de Manejo da UC que especifique o objeto ou potencial que poderá } \\
\text { ser explorado em cada unidade. }\end{array}$ \\
\hline 7 & Luiz Claudio Marcolino & $\begin{array}{l}\text { Acrescenta ao artigo } 4^{\circ} \text { o seguinte inciso VII: } \\
\text { Mecanismos que garantam a prioridade para comunidades, especialmente } \\
\text { tradicionais, serem beneficiárias diretas para possíveis rendimentos e } \\
\text { atividades econômicas. }\end{array}$ \\
\hline
\end{tabular}

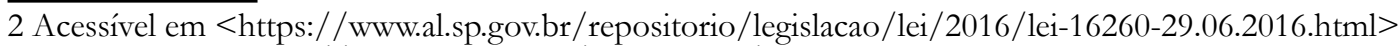

3 Acessível em <https://www.al.sp.gov.br/propositura/?id=1130646> 


\begin{tabular}{|l|l|l|}
\hline $\mathbf{N}^{\mathbf{0}}$ Emenda & Autores/Deputados & Síntese do Texto da emenda proposta (pela autora) \\
\hline 8 & Luiz Claudio Marcolino & $\begin{array}{l}\text { Acrescenta } ₫ 2^{\circ} \text { ao artigo } 2^{\circ}: \text { Terão prioridade na concessão entidades sem } \\
\text { finalidade lucrativa, em especial Organizações da Sociedade Civil de Interesse } \\
\text { Público. }\end{array}$ \\
\hline 9 & Luiz Claudio Marcolino & $\begin{array}{l}\text { Propõe ao “caput” do artigo } 1^{\circ} \text { a alteração do prazo de } 30 \text { para } 10 \text { anos para } \\
\text { a concessão. }\end{array}$ \\
\hline 10 & Luiz Claudio Marcolino & Propõe a vedação da renovação da concessão ao final do prazo \\
\hline 11 & Luiz Claudio Marcolino & $\begin{array}{l}\text { Propõe a exclusão do inciso I do artigo } 1^{\circ} \text {, excluindo a Cantareira, o Pico do } \\
\text { Jaraguá e o Horto florestal de Campos do Jordão. }\end{array}$ \\
\hline
\end{tabular}

Fonte: Resumo elaborado pela autora com base nos dados disponibilizados pela Assembleia Legislativa do Estado de São Paulo (ALESP), acessível em<www.al.sp.gov.br/propositura /?id=1130646. 2013>.

Dia 30 de junho de 2016 foi publicada, em Diário Oficial do Estado de São Paulo, a Lei 16.260/2016. Foi publicado, também, o Veto Parcial do Governador, vetando o item 4 do $\int 1^{\circ}$ do artigo $3^{\circ}$, sobre o inciso VII do artigo $4^{\circ}$ e sobre o artigo $6^{\circ}$. O item 4 do $\int 1^{\circ}$ do artigo $3^{\circ}$ fazia "a exigência de comprovação de capital social integralizado equivalente a no mínimo $10 \%$ do valor estimado do contrato", e seu veto foi feito com a justificativa de que na Lei 8.666/93 há o $\ 3^{\circ}$, do artigo 31, que autoriza a exigência de capital mínimo de no máximo 10\% do valor estimado da contratação, por isso o item 4 estaria contrariando essa regra geral. O inciso VII do artigo $4^{\circ}$ diz que deveriam constar no contrato condições para a restituição das áreas e bens ao Estado, sem indenização, tanto ao término do contrato como em qualquer hipótese de rescisão. A justificativa para o veto é a de que há um erro em colocar as duas condições de fim de contrato num mesmo artigo. O Art. $6^{\circ}$ cita que dos recursos obtidos com as concessões, até $50 \%$ e não menos que $25 \%$, deveriam ser destinados para a própria unidade; até $50 \%$ e não menos que $15 \%$ para outras unidades. A justificativa para o veto deste artigo gira em torno da informação de que ele dispõe sobre os critérios de aplicação de modo diverso, não contemplando a hipótese de regularização fundiária das UCs do Grupo, pois na Lei 9.985/2000, Artigo 35, prescreve que até 50\% e não menos que 25\% devem ser destinados para este fim.

Noticias

Diversas notícias foram publicadas desde a entrada do PL 249 na ALESP (Assembleia Legislativa de São Paulo), em jornais como a Folha de São Paulo, G1 e blogs de ONGs (para uma descrição mais detalhada ver Lopes 2016). Das notícias analisadas, identificamos posicionamentos antagônicos e em alguns casos narrativas mais descritivas. A seguir sintetizamos alguns aspectos que se destacaram.

Participação e debate: Diálogo insuficiente com comunidades tradicionais diretamente afetadas pelas UCs (Rolnik 2016); falta de debate com especialistas em conservação (Rolnik 2016; Arbex 2016); desconsideração de apontamentos e sugestões feitos pelo Ministério Público, seu corpo técnico e pesquisadores de universidades como garantias para a restauração florestal das áreas de preservação nas UCs com espaços concedidos, os direitos das comunidades tradicionais que vivem nesses locais, que também não foram citadas na Lei. (Girardi e Leite 2016); ausência de diretrizes mínimas para escolha, nos editais de concessão, do que exatamente poderá ou não ser explorado comercialmente pela iniciativa privada em cada um desses parques listados na Lei, (Rolnik 2016). Expectativas: Foram noticiadas posições favoráveis, que retratavam a expectativa de aumento de visitação por meio da melhoria de infraestrutura (como portaria, centro de visitação, sinalização de trilhas, banheiros e acessibilidade, por exemplo) e serviços (como restaurantes e lojas de souvenires) (Oliveira, 2015; O ECO 2016) que são precários em muitas UCs (O ECO 2016). 
Imparcialidade: Algumas notícias apresentaram a tramitação do PL de forma descritiva e, a princípio, imparcial. No entanto, uma delas destacou declarações da então Secretária de Meio Ambiente, Patrícia Iglecias, muito favoráveis à proposta, sem contrapor com outras opiniões (Domingos 2016).

Tempo de tramitação: Durante e após a aprovação, foram noticiadas manifestações de descontentamento (Oliveira 2015). Algumas notícias destacaram a rapidez na votação e aprovação da lei, após quase um ano sem discussões e sem a aprovação do CONSEMA (Girardi e Leite 2016). Foram reportadas críticas acerca do tempo de tramitação (3 anos) em contraposição à votação efetuada em regime de urgência (Oliveira 2015; O ECO 2016;). Também ganhou espaço a divulgação do pedido de adiamento de votação e a ação de inconstitucionalidade do PL (O ECO 2014), incluindo a tramitação de parecer contrário ao PL dentro da ALESP e o pedido de revogação da lei, posterior à sua aprovação (O ECO 2014). Ivan Castanheiro, do ministério público estadual, afirma em declaração à Rede Brasil Atual, em 2015, que: "A concessão da gestão a empresas com fins lucrativos contraria a Lei Federal 9.790/99, que qualifica as OSCIPs [Organização da Sociedade Civil de Interesse Público] e disciplina o chamado termo de parceria, trazendo uma crise de legalidade da norma estadual em relação à federal" (Oliveira 2015).

\section{Ofício e outros documentos}

A votação e aprovação da Lei 16260/16 foi realizada com a inclusão de emenda aglutinativa, que fez com que o PL fosse votado em regime de urgência. O PL não foi, a princípio, redigido pela SMA nem teve participação efetiva de seu corpo técnico na elaboração.

Como já citado, a prefeitura de Ubatuba enviou um ofício em 10/06/2016 com manifestação contrária a inclusão das UCs da região em qualquer tentativa de concessão sem o prévio conhecimento da prefeitura e da realização de audiências públicas no município. Eles exigiram completa transparência e ampla discussão. Uma das maiores preocupações dos munícipes e da prefeitura é com relação às comunidades tradicionais que têm território dentro de algumas destas UCs. Apesar da manifestação da Prefeitura local, constam na lista final da Lei 16.260 cinco parques na região do litoral norte, mas nenhum localizado na cidade de Ubatuba.

Além deste ofício, houve um inquérito civil pela cidade de Itirapina, assinado pelo GAEMA (Grupo de Atuação Especializado em Meio Ambiente), PCJ- Piracicaba ${ }^{4}$. Os objetivos apresentados envolvem a averiguação da constitucionalidade da Lei e se os requisitos exigidos nos editais de licitação serão suficientes, o acompanhamento das atividades realizadas pelo concessionário, caso haja a implementação de concessão na Estação Ecológica (EE) de Itirapina, a forma como o concessionário pretende combater a invasão de espécies exóticas na EE e relembra a importância da existência do remanescente de cerrado presente na UC de que se trata, para a biodiversidade local e regional (São Paulo 2015).

A moção sobre a tramitação do PL 249/2013 emitida pelo Conselho Universitário da Universidade Estadual Paulista (Quadro 1) visa manifestar-se publicamente sobre o assunto e cita a quantidade de pesquisas, ensino e projetos de extensão relacionados às UCs paulistas, que afirmam e reafirmam a importância destes locais e requisita a retirada do projeto transformado em Emenda aglutinativa de pauta, para que haja melhor discussão com todos os segmentos da sociedade.

\section{Vetos, brechas e fragilidades}

No Artigo $1^{\circ}$ da Lei 16260/16 há algumas lacunas, como por exemplo, o trecho em que é citado que a exploração madeireira somente será permitida em áreas previstas no PM para este fim, mas não cita a mesma condição para as áreas inerentes ao Ecoturismo.

4 Acessível em <https://www.al.sp.gov.br/spl/2015/08/Acessorio/1269956_50253321_Acessorio.pdf> 
Os vetos do governador Geraldo Alckmin foram justificados, mas o risco de se homologar a lei sem nenhuma informação específica sobre a devolução das áreas, móveis, imóveis e benfeitorias no final do prazo da concessão pode ser grande, pois isso abre brechas para que as empresas reivindiquem a posse das áreas e exijam indenização pelas benfeitorias, gerando gasto desnecessário ao órgão público que já deveria ter assegurado o direito de retorno à posse das áreas. O que parece uma evidência de que a rapidez na aprovação da lei afetou a clareza e a rigidez das informações contidas no texto da mesma.

A principal argumentação para a concessão no país é o ganho econômico que isso traria para as próprias UCs, mas a lei foi aprovada com veto no Artigo $4^{\circ}$ que falava sobre a distribuição da verba, justificando com o Art. $35^{\circ}$ do SNUC, mas quanto mais completas as diretrizes da própria lei em questão, melhor, ou seja, seria importante conter na Lei 16260/16 informações sobre para onde o dinheiro gerado deveria ir e sobre a sua distribuição ${ }^{5}$. A consequência negativa destas novas concessões será que a maioria das UCs do Estado de SP passará a ter cobrança de ingresso, o que pode começar a excluir parte da população que, por não ter condições de pagar, não terá acesso às visitas e melhorias nas UCs. Isto novamente deve ser garantido e exigido nos editais e contratos, que podem e devem conter cláusulas referentes a descontos para moradores locais, e pessoas de baixa renda, além de poderem apresentar propostas de aumento do valor do ingresso somente uma vez por ano ou acompanhando a inflação, ou até mesmo limite de valor a ser cobrado como existe no contrato de exploração de serviços de transporte ferroviário de passageiros na Estrada de Ferro do Corcovado no PARNA da Tijuca.

Vale ressaltar que o veto do Governador para o item 4 do $\int 1^{\circ}$ do artigo $3^{\circ}$ foi uma reivindicação de associações relacionadas ao ecoturismo em UCs, pois não haveria possibilidade dessas ONGs e organizações de moradores comprovarem renda, pois não tem capital, foi um veto comemorado por ser um ganho para as empresas pequenas.

A Lei 16260/16 cita que as atividades a serem desenvolvidas nas áreas devem seguir à risca o PM e somente serão concedidas áreas citadas no mesmo que sejam destinadas ao fim de ecoturismo ou exploração florestal. Mas é importante sabermos que as seguintes UCs que estão incluídas na Lei 16260/2016 não possuem PM: Parque Estadual Caverna do Diabo, Estação Experimental de Araraquara, Estação Experimental de Itapeva, Floresta Estadual Águas de Santa Bárbara, Floresta Estadual de Batatais, Floresta Estadual de Cajuru, Floresta Estadual de Pederneiras, Floresta Estadual de Piraju. Isto pode ser um problema, pois sem o PM elas poderão ser excluídas de alguma concessão ou terem o PM feito às pressas e com estudos feitos sem a real atenção a todos os pontos que devem ser abordados.

Apesar de diversos ambientalistas estarem receosos em relação à Lei 16260/16, e membros da população em geral não estarem seguros em relação a como acontecerão as licitações e concessões, não podemos deixar de citar que ainda há espaço para atuação, em cada Edital de concessão, onde devem haver as normas e diretrizes para que o contrato seja feito.

Neste momento, estudos técnicos, informações e acompanhamento são essenciais. Vale lembrar também que estes editais passarão pelo CONSEMA, como está descrito na Lei e após a assinatura do contrato quem fiscalizará será a Fundação Florestal, por uma comissão nomeada pelo regulamento. Espera-se uma postura correta desses órgãos e fiscalização rígida por parte da comunidade.

5 Como ressalta Rodrigues e Godoy em seu trabalho: "Atuação pública e privada na gestão de Unidades de Conservação: aspectos socioeconômicos da prestação de serviços de apoio à visitação em parques nacionais" deve haver uma ampla divulgação no fluxo de recursos financeiros que serão aplicados, para que haja um acompanhamento por parte não só dos visitantes, mas da população de um modo geral, dos efeitos dos investimentos. Além disso, o autor afirma que é importantíssimo evidenciar também que o aporte destes recursos obtidos pelo poder público não deve ser encarado como a principal forma de compensar a falta de recursos no orçamento público, e sim como um apoio para impulsionar a melhoria na gestão da própria visitação (RODRIGUES; GODOY, 2013) 
Nos anos seguintes à aprovação da Lei, houveram alguns acontecimentos que valem ser citados. Um exemplo foi no Pico do Jaraguá onde existia uma reserva indígena com mais de 530 hectares no Parque Estadual do Jaraguá (portaria $n^{\circ} 581$ de 2015). Nesta área, aldeia Tekoa Itakupe, viviam 150 famílias (em média 700 indígenas) da etnia Guarani. A portaria foi revogada pelo Ministério da Justiça, em agosto de 2017, com a justificativa de "erro administrativo". Em notícia divulgada no site de notícias G1 SP, há o seguinte trecho "Os índios que estão desde quarta (13/09/2017) no Parque Estadual do Jaraguá, na Zona Norte de São Paulo, ocuparam as torres do Pico do Jaraguá que abrigam antenas de empresas de telefonia, rádio e TV nesta quinta (14). Eles exigem diálogo sobre a decisão do Governo Federal de anular a demarcação de terras indígenas”. O Parque Estadual do Jaraguá é uma das UCs que consta na lista anexada a Lei 16.260/2016 e o governo de São Paulo previa concessão de serviços específicos nessas áreas (Jornal Online G1 2017)

O primeiro Parque Estadual que abriu Edital para a concessão foi o de Campos do Jordão, em dezembro de 2018 com área disponibilizada de 473,15 hectares. O local foi escolhido para ser o piloto para as próximas concessões previstas em outras UCs do estado. Apenas uma empresa (a Urbanes Empreendimentos, do Rio Grande do Sul) se interessou e entregou proposta para a concessão em Campos do Jordão. Serão destinados e pagos mais de 45 milhões de reais em investimentos, além da outorga de 80 milhões. Em notícia no Jornal online G1, há afirmação sobre o congelamento da tarifa de entrada nos 18 meses iniciais ( $\$ 15)$, mas que poderá haver reajuste de $\mathrm{R} \$ 4$. O título da notícia chama atenção por utilizar o termo "privatizar", e não conceder, ao se referir à licitação (G1 2019)

Seguindo na lista de UCs do anexo da Lei 16.260, o Parque Estadual da Cantareira, abriu Edital também em dezembro de 2018, mas ao contrário do primeiro caso não houve nenhuma empresa interessada em participar do processo de licitação, e o governo afirmou que a previsão era de que fossem investidos cerca de $\mathrm{R} \$ 6,2$ milhões na exploração do ecoturismo local (Mancuso 2019).

\section{CoNSIDERAÇÕES FINAIS}

Após consideração da legislação em vigência no país e avaliação das dificuldades na gestão das UCs, podemos dizer que a Lei 16260/2016, originária do PL 249/2013, foi criada em um cenário no qual o Poder Público não esgotou completamente todos os mecanismos existentes para suprir a insuficiência financeira e de recursos humanos nas UCs. Além disso, a tramitação do PL e aprovação da Lei apresentam alguns pontos questionáveis, como a falta de debate com a população em geral, a incerteza sobre o suporte técnico prestado para a redação do PL (indicada pelos equívocos no anexo da Lei e outros pontos destacados na seção anterior), a forma com que ocorreu a votação (via Emenda aglutinativa), suas brechas e indefinições (apontadas na seção "Vetos, brechas e fragilidades").

No entanto, a Lei 16260/2016 ainda deixa espaço para atuação de ONGs, do Ministério Público e outros especialistas e instituições, por meio de apoio técnico e legal na elaboração principalmente dos editais, mas também na elaboração e revisão dos PMs (exigidos para que se possa realizar a concessão), no desenvolvimento dos contratos de concessão e por meio da participação nas audiências públicas obrigatórias. Nestas etapas que precedem a concessão há espaço para garantir e reivindicar a proteção integral das UCs, o acesso ao público e exigir os investimentos necessários.

O fato da Lei 16260/16 regulamentar as concessões em 25 UCs do Estado de SP, faz dela uma legislação específica e esta Lei pode organizar melhor as concessões que já estavam ocorrendo no Estado com base em outras leis. A citação de somente haver permissão para exploração em áreas previstas no PM para tais finalidades é um ponto positivo da Lei, que além de garantir a compatibilidade das atividades previstas na concessão com a 
finalidade de proteção das áreas a serem concedidas, depende da oitiva do CONSEMA e de audiência pública para a aprovação.

Os pontos negativos da Lei incluem o tempo destinado para estas concessões (30 anos) - o que pode representar um período muito longo, a depender da qualidade da atuação da concessionária - e a ausência de informações claras sobre como os recursos arrecadados serão destinados. Outro ponto questionável está no fato de não terem existido discussões suficientes em torno do PL e de que o público em geral não estava devidamente informado sobre o assunto, pois ainda existiam dúvidas e questionamentos em torno do texto da Lei. Os artigos vetados na Lei deveriam ter sido substituídos por informações relacionadas a eles, para garantir clareza e objetividade. A simples remoção deles da redação final deixa algumas brechas.

O ponto negativo mais importante reside no fato de a concessão ser sobre as áreas e não sobre os serviços, pois, por exemplo, para a implantação de um restaurante não é necessária à concessão da área em si. A concessão da área pode trazer consequências e conflitos para a gestão e controle das UCs. Além disso, a falta de divulgação dos editais de concessão e o prazo para submissão de propostas (cerca de 45 dias no caso de PE Campos do Jordão e PE da Cantareira), dificulta a ampla competição e o entendimento do público geral sobre o que está em jogo. Da mesma forma, pequenas organizações civis ou lideranças locais (comunidades tradicionais e indígenas) permanecem alheias aos processos de concessão, por não terem a expertise necessária para concorrer aos editais como é tipicamente o perfil das empresas que ganham as licitações.

O engajamento da equipe gestora da UC no processo de concessão será o próximo passo essencial e imprescindível para que os objetivos de conservação sejam contemplados e para que a relação com o entorno priorize a participação social das populações locais e das comunidades tradicionais relacionadas às UCs em questão. O turismo pode e deve ser realizado de maneira responsável e sempre em conexão com a conservação e educação ambiental. Espera-se que este trabalho tenha demonstrado as possibilidades de atuação de pontos positivos e importantes dessa Lei, por meio do apoio e cobrança dos especialistas e ambientalistas pela efetividade, por parte dos órgãos responsáveis, na elaboração dos editais, termos de referência e contratos de concessões que não fujam aos principais propósitos das UCs.

\section{Agradecimentos}

Agradeço a Profa. Dra. Rosa Maria Feiteiro Cavalari do Departamento da Educação da UNESP Rio Claro, pelo auxílio e contribuições importantes a descrição dos métodos do trabalho, a Profa. Dra. Maria Inez Pagani pela supervisão e revisão do texto e a Ms. Julia Camara Assis, por ser uma orientadora incrível e uma pessoa sensacional. Agradeço à Universidade Estadual Paulista, que sendo pública, me deu a oportunidade de acessá-la e que deve continuar assim sempre, com cada vez mais acesso para todos. O presente trabalho foi realizado com apoio para JCA da Coordenação de Aperfeiçoamento de Pessoal de Nível Superior-Brasil (CAPES) - Código de Financiamento 001.

\section{REFERÊNCIAS}

Arbex, T. 2016. Alckmin amplia proposta e agora quer 'privatizar' 25 parques de São Paulo. Disponível em: <http:// www1.folha.uol.com.br/cotidiano/2016/06/1778980-governo-alckmin-quer-conceder-25-parques-a-iniciativa-privada. shtml>. Acesso em 09/08/2016

Bardin L. 2004. Análise de conteúdo, $3^{a}$ edição. Lisboa: Edições 70, v. 70, 223 p. 
Barros, MIA. 2003. Caracterização da visitação, dos visitantes e avaliação dos impactos ecológicos e recreativos do planalto do Parque Nacional do Itatiaia. Dissertação de mestrado. Universidade de São Paulo.

Bensusan, N. 2006. Conservação da biodiversidade em áreas protegidas. $1^{\circ}$ edição, FGV Editora, 176 p.

Braga, AS. 2015. Viabilização do uso público de parques nacionais e a disponibilização por particulares de serviços de apoio à visitação. Brasília, UNICEUB.

Brasil. 1988. Constituição da República Federativa do Brasil. Cap. VI - Do Meio Ambiente, Art. 225. Brasília, DF. Disponível em: <http://www.planalto.gov.br/ccivil_03/constituicao/constituicaocompilado.htm>. Acesso em 09/12/2015.

Brasil. Constituição da República Federativa do Brasil. 1993. Casa Civil. Subchefia para Assuntos Jurídicos. Lei no 8.666 de 21 de junho de 1993. Brasília, DF. Disponível em: <http://www.planalto.gov.br/ccivil_03/leis/L8666cons.htm>. Acesso em 02/04/2016.

Brasil. 2000. Constituição da República Federativa do Brasil. Lei no 9.985 de 18 de julho de 2000. Brasília, DF. Disponível em: <http://www.planalto.gov.br/ccivil_03/leis/L9985.htm>. Acesso em 29/03/2016.

Brasil. 2002. Constituição da República Federativa do Brasil. Decreto $\mathbf{n}^{\circ} 4.340$ de 22 de agosto de 2002. Brasília, DF. Disponível em: <http://www.planalto.gov.br/ccivil_03/decreto/2002/d4340.htm>. Acesso em 01/04/2016.

Brasil. 2004. Constituição da República Federativa do Brasil. Lei no 11.079 de 30 de dezembro de 2004. Brasília, DF. Disponível em: <http://www.planalto.gov.br/ccivil_03/_ato2004-2006/2004/lei/111079.htm>. Acesso em 01/04/2016.

Brasil. Ministério do Meio Ambiente. 2009. Pilares para a Sustentabilidade Financeira do Sistema Nacional de Unidades de Conservação. Secretaria de Biodiversidade e Florestas, Departamento de Áreas Protegidas. Brasília, DF.

Brasil. Ministério do Meio Ambiente. 2011. ICMBio. Governo assina acordo para permitir PPPs em Unidades de Conservação. Disponível em: <http://www.icmbio.gov.br/portal/comunicacao/noticias/20-geral/2184-governo-assinaacordo-para-permitir-ppps-em-unidades-de-conservacao.html>. Acesso em: 29/03/2016

Brasil. Ministério do Meio Ambiente. 2018. Cadastro Nacional de Unidades de Conservação - CNUC. Tabela Consolidada das Unidades de Conservação. Disponível em: < http://www.mma.gov.br/images/arquivo/80238/CNUC_FEV18\%20 -\%20B_Cat.pdf>. Acesso em: 31/07/2018.

Brasil. Ministério do Planejamento Desenvolvimento e Gestão. 2011. Planejamento e Meio Ambiente assinam acordo para PPP em Unidades de Conservação. Brasilia. Disponível em: < http://www.planejamento.gov.br/assuntos/assuntoseconomicos/noticias/planejamento-e-meio-ambiente-assinam-acordo-para>. Acesso em 31/08/2016.

Brito, DMC et al. 2010. Conflitos socioambientais na gestão de Unidades de Conservação: o caso da Reserva Biológica do Lago Piratuba/AP. 375 p. Tese - Universidade Federal do Pará, Instituto de Filosofia e ciências Sociais.

Domingos, R. 2016. Concessão pode gerar cobrança de entrada em parques, diz secretária. Disponível em: < http:// g1.globo.com/sao-paulo/noticia/2016/06/concessao-pode-gerar-cobranca-de-entrada-em-parques-diz-secretaria.html>. Acesso em 08/08/2016.

Faria, HH. 2004. Eficácia de gestão de unidades de conservação gerenciadas pelo Instituto Florestal de São Paulo, Brasil. 401 p. Tese - Universidade Estadual Paulista, Faculdade de Ciências e Tecnologia. 
Farias, TQ. 2006. Aspectos gerais da política nacional do meio ambiente - comentários sobre a Lei $\mathrm{n}^{\circ}$ 6.938/81. Âmbito Jurídico, 9 (35).

G1, Globo SP. 2017. Índios ocupam torres no Pico do Jaraguá em protesto contra anulação de demarcação de terras. Disponível em:< https://g1.globo.com/sao-paulo/noticia/indios-ocupam-torres-no-pico-do-jaragua-em-protesto-contraanulacao-de-demarcacao-de-terras.ghtml>. Acesso em 27/08/2019.

G1, Globo Vale do Paraíba e Região. 2019. Licitação para privatizar parque estadual em Campos tem apenas uma interessada. Disponível em: <https://g1.globo.com/sp/vale-do-paraiba-regiao/noticia/2019/01/24/licitacao-paraprivatizar-parque-estadual-em-campos-tem-apenas-uma-interessada.ghtml> Acesso em 27/08/2019.

Girardi, G; Leite, F. 2016. Assembleia aprova projeto que 'privatiza' 25 parques de SP. Disponível em: < http:// sustentabilidade.estadao.com.br/noticias/geral,assembleia-aprova-projeto-que-privatiza-25-parques-de-sp,10000055809>. Acesso em 07/07/2016

Gorini APF; Mendes, EF; Carvalho, DMP. 2006. Concessão de serviços e atrativos turísticos em áreas naturais protegidas: o caso do Parque Nacional do Iguaçu. BNDES setorial, 24: 171-209.

ICMBio. 2011. Procuradoria Federal Especializada. Parecer nº 02070.002323/2011-09. Brasília, DF.

Iglecias, P. 2015 Apresentação do PL 249/2013. Secretaria do Meio Ambiente. Disponível em: < http://www.al.sp.gov.br/ repositorio/bibliotecaDigital/21314_arquivo.pdf> Acesso em 26/11/2015.

Lopes, Fernanda Nogueira. Concessão de uso em Unidades de Conservação de Proteção Integral: um panorama sobre as possíveis implicações do PL 249/2013. Universidade Estadual Paulista. Rio Claro/ São Paulo. 2016.

Mancuso, Filippo. 2019. Concessão do Parque da Cantareira à iniciativa privada não tem interessados; governo de SP fará nova licitação. Disponível em: <https://g1.globo.com/sp/saopaulo/noticia/2019/02/04/concessao-do-parqueda-cantareira-a-iniciativa-privada-nao-tem-interessados-governo-de-sp-fara-nova-licitacao.ghtml> Acesso em 27/08/2019.

Medeiros, R.; Young; C.E.F.; Pavese, H. B. \& Araújo, F. F. S. 2011. Contribuição das unidades de conservação brasileiras para a economia nacional. Sumário Executivo. 44 p. UNEP-WCMC. Brasília.

Mulongoy, KJ.; Chape, S. 2003. Protected areas and biodiversity: an overview of key issues. Convention on Biological Diversity (CBD). Cambridge. World Conservation Monitoring Centre. 52 p.

Neves, LH. 2012. Delegação de serviços de apoio à visitação. Disponível em: <http://www.semeia.org.br/index.php/ $\mathrm{pt} /$ nossas-iniciativas/engajamento-da-iniciativa-privada/item/download/110>. Acesso em 31/03/2016

O ECO, Jornalismo Ambiental. 2016. Assembleia de São Paulo aprova concessão de 25 áreas protegidas. São Paulo. Disponível em: < http://www.oeco.org.br/noticias/assembleia-de-sao-paulo-aprova-concessao-de-25-areas-protegidas/>. Acesso em 09/08/2016.

O ECO, Jornalismo ambiental. 2014. Projeto paulista legaliza concessões em parques estaduais. São Paulo. Disponível em: < https://www.oeco.org.br/reportagens/27999-projeto-paulista-legaliza-concessoes-em-parques-estaduais/>. Acesso em 09/08/2016. 
Oliveira, C. 2015. Prefeitura de Ubatuba reivindica controle do núcleo Picinguaba do Parque da Serra do Mar. Disponível em: < http://www.redebrasilatual.com.br/ambiente/2015/06/prefeitura-de-ubatuba-quer-prioridade-emconcessao-de-uso-do-parque-da-serra-do-mar-5589.html>. Acesso em 09/08/2016.

Oliveira, André Gustavo Campos de. 2017. Unidades de conservação: desafios e alternativas de gestão econômica dos parques nacionais. 141 f. Dissertação (Mestrado em Gestão Econômica do Meio Ambiente) Universidade de Brasília, Brasilia.

Oliveira, Cida de. 2015. Promotor afirma que projeto de Alckmin sobre áreas florestais é inconstitucional. Disponível em: < https://www.redebrasilatual.com.br/ambiente/2015/06/cheque-em-branco-pl-de-alckmin-esta-em-conflito-com-acom-lei-paulista-1529/>. Acesso em 27/08/2019.

Rolnik, R. 2016. Entregar nossos parques estaduais a empresas privadas é solução? Disponível em: $<$ https:// raquelrolnik.wordpress.com/2016/06/09/entregar-nossos-parques-estaduais-a-empresas-privadas-e-solucao/>. Acesso em 02/07/2016.

Rodrigues, CGO; Godoy, LRC. 2013. Atuação pública e privada na gestão de Unidades de Conservação: aspectos socioeconômicos da prestação de serviços de apoio à visitação em parques nacionais. Desenvolvimento e Meio ambiente. 28: 75-88.

São Paulo. 2013. Assembleia Legislativa do Estado de São Paulo. Projeto de Lei no 249/2013. Disponível em:< http://www. al.sp.gov.br/propositura/?id=1130646>. Acesso em 15/03/2016.

São Paulo. 2015. Inquérito Civil no14.1096.000004/2013-0. Grupo de Apoio Especial em Defesa do Meio Ambiente- Núcleo PCJ- Piracicaba. Disponível em: <https://www.al.sp.gov.br/spl/2015/08/Acessorio/1269956_50253321_Acessorio.pdf>. Acesso em 02/07/2016.

São Paulo. 2016. Assembleia Legislativa do Estado de São Paulo. Secretaria Geral Parlamentar. Lei no 16260 de 29 de junho de 2016. Disponível em <http://www.al.sp.gov.br/norma/?id=178640>. Acesso em 01/07/2016.

Socioambiental, Instituto. 2014. Ambientalistas e organizações ligadas ao turismo sustentável divulgam manifesto em defesa de UCs. Disponível em: < https://www.socioambiental.org/pt-br/noticias-socioambientais/ambientalistas-eorganizacoes-ligadas-ao-turismo-sustentavel-divulgam-manifesto-em-defesa-de-ucs>. Acesso em 27/08/2019.

Zimmermann, A. Rodrigues, CGO. Andrade, J. 2005. Visitação em Parques Nacionais: oportunidades para participar, vivenciar e conservar. Revista Caderno Virtual de Turismo, Anais I SAPIS. 
Apêndice 1 - Detalhes da Tramitação do PL 249/2013

O PL 249, de 30 de abril de 2013 de autoria do Governador Geraldo Alckmin, primeiramente autorizava a Fazenda do Estado a conceder o uso de áreas públicas inseridas em algumas UCs (Parque Estadual Campos do Jordão, Parque Estadual da Cantareira, Parque Estadual do Jaraguá) e as áreas públicas da Estação Experimental de Itirapina e Floresta Estadual de Cajuru. O PL passou por uma Tramitação de Urgência e esteve em pauta dos dias 03 a 07 de dezembro de 2013, período em que recebeu 11 emendas (Quadro S3) e uma Emenda Aglutinativa adicionando o nome de 25 Parques (Anexo A da Lei). O PL foi aprovado e publicado na Lei no 16260/2016. Alguns Parques estão com a grafia errada e com os nomes errados no documento: o PE DE ILHA BELA (a grafia correta é Ilhabela), PE JARAGUÁ (no qual o nome correto é PE do Jaraguá), PPE CANTAREIRA (o correto seria PE Cantareira), o PE SERRA DO MAR - NÚCLEO SÃO PAULO (este núcleo não existe, o núcleo mais próximo de São Paulo é o Curucutu, o que nos leva a crer que este seria o nome correto do núcleo a que se referiam) e o CAMINHO DO MAR (o nome correto é Parque Caminhos do Mar; Anexo A da Lei).

No dia 03 de junho de 2013 ocorreu votação na Comissão de Meio Ambiente e Desenvolvimento Sustentável, obtendo resultado favorável ao projeto e às emendas 4, 5 e 7 e contrário às emendas 1,2,3,6,8,9,10 e 11 . No dia 04 de junho de 2013 o PL foi votado na Comissão de Infraestrutura com 3 votos favoráveis ao parecer e 5 contrários. A deliberação foi de rejeição ao voto do Relator, pela comissão de infraestrutura em Reunião Ordinária, e foi designado o Deputado Dilador Borges para redigir o vencedor favorável, este se pronunciou favorável às emendas 4 e 5 , e contrário às emendas 1,2,3,6,7,8,9,10 e 11. O projeto seguiu para apreciação da Comissão de Constituição, Justiça e Redação no dia 07 de junho de 2013, onde obteve 7 votos favoráveis e foi aprovado como Emenda Aglutinativa com rejeição das emendas propostas e teve como parecer o voto do Deputado Gilmaci Santos, propondo redação final.

Após isso, no dia 08 de junho de 2016 foi protocolado junto ao Gabinete do Senhor Governador Geraldo Alckmin ofício originário do PL, aprovado pela Assembleia Legislativa do Estado de São Paulo (ALESP). Recebido pelo Governador com prazo de 15 dias para sanção ou veto. No dia 09 de junho o Deputado Fernando Capez, presidente da ALESP assinou o Autógrafo da Lei 16260/2016. No dia seguinte (10/06) foi publicado ofício da Prefeitura Municipal de Ubatuba (Mat. Sup. 2), manifestando-se contra a inclusão dos Parques da região na Lei.

Dia 30 de junho de 2016 foi publicada, em Diário Oficial do Estado de São Paulo, a Lei 16.260/2016 que "Autoriza a Fazenda do Estado a conceder a exploração de serviços ou o uso, total ou parcial, de áreas em próprios estaduais que especifica e dá providências correlatas". Foi publicado, também, o Veto Parcial do Governador, vetando o item 4 do $\int 1^{\circ}$ do artigo $3^{\circ}$, sobre o inciso VII do artigo $4^{\circ}$ e sobre o artigo $6^{\circ}$.

$\mathrm{O}$ item 4 do $\int 1^{\circ}$ do artigo $3^{\circ}$ fazia "a exigência de comprovação de capital social integralizado equivalente a no mínimo 10\% do valor estimado do contrato", e seu veto foi feito com a justificativa de que na Lei 8.666/93 há o \ $3^{\circ}$, do artigo 31, que autoriza a exigência de capital mínimo de no máximo $10 \%$ do valor estimado da contratação, por isso o item 4 estaria contrariando essa regra geral. O inciso VII do artigo $4^{\circ}$ diz que deveriam constar no contrato condições para a restituição das áreas e bens ao Estado, sem indenização, tanto ao término do contrato como em qualquer hipótese de rescisão. A justificativa para o veto é a de que há um erro em colocar as duas condições de fim de contrato num mesmo artigo. $\mathrm{O}$ Art. $6^{\circ}$ cita que dos recursos obtidos com as concessões, até $50 \%$ e não menos que $25 \%$, deveriam ser destinados para a própria unidade; até 50\% e não menos que 15\% para outras unidades. A justificativa para o veto deste artigo gira em torno da informação de que ele dispõe sobre os critérios de aplicação de modo diverso, não contemplando a hipótese de regularização fundiária das UCs do Grupo, pois na Lei 9.985/2000, Artigo 35, prescreve que até 50\% e não menos que $25 \%$ deve ser destinado este fim.

Para a obtenção de informações e esclarecimentos de algumas dúvidas enviamos e-mails para os Deputados. Apenas o Deputado Roberto Trípoli respondeu ao e-mail com informações de que a ALESP já havia recebido o projeto pronto do Poder Executivo Estadual para aprovação, informou que os 25 parques foram incluídos na Lei 16260/2016 por uma Emenda Aglutinativa através de discussões em reunião. Além disso, enviou a Lei já aprovada e homologada em anexo ao e-mail. 